\title{
Effect of Medium Change on the Development of In Vitro Matured and Fertilized Bovine Oocytes Cultured in Medium Containing Amino Acids
}

\author{
Koji IKEDA, Yoshiyuki TAKAHASHI and Seiji KATAGIRI \\ Laboratory of Theriogenology, Department of Veterinary Clinical Sciences, Graduate School of Veterinary Medicine, Hokkaido \\ University, Sapporo 060-0818, Japan
}

(Received 16 June 1999/Accepted 14 September 1999)

ABSTRACT. Bovine in vitro matured and fertilized oocytes were cultured for $153 \mathrm{hr}$ in groups of 3 or 30 in $30 \mu l$ of modified synthetic oviduct fluid medium supplemented with amino acids. The concentration of ammonium in culture medium at 153 hr of culture was significantly decreased by medium change at $72 \mathrm{hr}$ of culture. However, regardless of embryo density, medium change had no beneficial or detrimental effect on the development of bovine embryos. Increase in the development to blastocysts and production of ammonium were observed when embryos were cultured in groups of 30 . These results indicated that the ammonium concentration detected in this culture system has a negligible effect on the development of bovine embryos to blastocysts.—KEY wORDS: ammonium, culture, embryo.

It is well known that amino acids added to culture media are beneficial for in vitro development of preimplantation embryos in mice [6, 11], sheep [7] and cattle [17]. Amino acids also increase the postimplantation development of mouse [9] and rat [23] embryos cultured in vitro. However, amino acids are metabolized by embryos and spontaneously break down at $37-39^{\circ} \mathrm{C}$ resulting in a significant level of ammonium in the medium [5-7]. Although the mechanisms of ammonium toxicity in somatic cells remain unclear, the detrimental effects of ammonium on the cells have been well documented [16]. Exposure of mouse embryos to ammonium in culture inhibits embryonic development [6], and induces fetal retardation and exencephaly [9].

When embryos are cultured in the medium containing amino acids, ammonium in the culture medium can be removed by medium change [5] or by in situ enzymatic conversion to glutamate [10]. The change of culture medium at 48 or $72 \mathrm{hr}$ intervals improved the in vitro development of mouse [6,10] and sheep [7] embryos and in vivo development of mouse embryos after transfer to recipient animals [9]. However, the effect of medium change on in vitro embryonic development was inconsistent in cattle [2,5]. Medium change at $48 \mathrm{hr}$ intervals had no beneficial or detrimental effect on bovine embryo development to blastocysts in high density (20-40 embryos, 1 embryo/ $\mu l$ ) [2], while a detrimental effect was observed at a lower density (4 embryos/30 $\mu$ ldrop or 5 embryos/50 $\mu l$ drop) [5]. The inconsistent results in cattle might be attributed to the differences in the culture system, especially in the embryo density during culture. In mouse [8, 21], sheep [7] and cattle [3, 4, 12], embryo culture in groups enhanced development in vitro. Improved development is probably due to embryotrophic factor(s) produced by the embryo itself $[8,13]$. Medium change removes both inhibitory and stimulatory substances. It is therefore conceivable that embryo density, which may relate the concentrations of those embryo metabolites and products, affects subsequent development after medium change. This study determined the effect of medium change on the development of bovine in vitro matured and fertilized oocytes under different embryo densities. We also examined the concentration of ammonium in the culture medium.

In vitro maturation and fertilization of bovine oocytes was performed using the method described by Takahashi et al. [18-20]. After in vitro fertilization, the cumulus cells were removed from oocytes by voltexing in HEPES-buffered Tyrode's medium [1]. The cumulus-free presumptive zygotes were washed three times with culture medium and then cultured in groups of 3 or 30 in $30 \mu l$ drops covered with paraffin oil for $153 \mathrm{hr}$ at $39^{\circ} \mathrm{C}$ in a humidified atmosphere of $5 \% \mathrm{O}_{2}, 5 \% \mathrm{CO}_{2}$ and $90 \% \mathrm{~N}_{2}$. Culture medium was modified synthetic oviduct fluid medium (mSOF; [17]) supplemented with $1 \mathrm{mM}$ glutamine (Sigma Co., St. Louis, MO, U.S.A.), premixture solutions of 12 essential amino acids for basal medium Eagle (Sigma) and 7 nonessential amino acids for minimum essential medium (Sigma), $5 \mathrm{mM}$ glycine (Sigma), $5 \mathrm{mM}$ taurine (Sigma), 10 $\mu \mathrm{g} / \mathrm{m} l$ insulin (Sigma), $1 \mathrm{mM}$ glucose (Kanto Chemical Co., Inc., Tokyo, Japan) and $3 \mathrm{mg} / \mathrm{ml}$ fatty acid-free BSA (Sigma). Microdrops of culture medium were preincubated overnight (10 to $12 \mathrm{hr}$ ) before use. After checking the cleavage rate at $72 \mathrm{hr}$ of culture, the embryos were washed three times with a fresh culture drop preincubated overnight and transferred to the fresh culture drop in the medium changed group. At $153 \mathrm{hr}$ of culture, the development to the blastocyst stage was assessed and the total cell number in blastocysts was counted using an air-drying method [17].

Concentrations of ammonium in the medium were measured by the enzymatic method using glutamate dehydrogenase (Determiner- $\mathrm{NH}_{3}$, Kyowa Medex Co., Ltd., Tokyo, Japan). Twenty five microlitters of the culture medium was taken into microtest tube and frozen at $-40{ }^{\circ} \mathrm{C}$ until measurement. The method of measurement was followed by the kit with slight modification for small volume 
of samples. Concentrations of ammonium in the culture medium incubated with or without embryos were measured at 0 and $153 \mathrm{hr}$ for the control group and at 0,72 and $153 \mathrm{hr}$ for the medium changed group.

Ammonium concentrations in the culture medium were $0.083 \pm 0.070 \mathrm{mM}(\mathrm{n}=16)$ at $0 \mathrm{hr}$ of culture and $0.053 \pm$ $0.035 \mathrm{mM}(\mathrm{n}=6)$ in fresh culture drop for medium change at $72 \mathrm{hr}$ of culture, respectively. As shown in Table 1, ammonium was generated even when the culture medium did not contain bovine zygotes. The increase in ammonium concentration in the culture medium was consistent with previous reports [5-7]. Ammonium was reported to be produced by mouse [6] and sheep [7] embryos in the culture medium containing glutamine and other amino acids. The present experiment confirmed ammonium production by bovine embryos especially when embryos were cultured from the zygote stage in high density. However, ammonium concentrations at $153 \mathrm{hr}$ of culture after medium change were similar regardless of embryo density (Table 1). This is probably due to the reduction in utilization of amino acids, such as glutamine, by the embryos at advanced stages [14, 15].

Ammonium concentration in culture medium was decreased by medium change (Table 1), therefore, it seemed beneficial to avoid prolonged exposure of embryos to a high concentration of ammonium by medium change. However, embryo density, but not medium change affected embryonic development (Table 2). There was no detectable interaction between the effect of medium change and that of embryo density. Carolan et al. [2] reported that medium change every $48 \mathrm{hr}$ did not have any beneficial or detrimental effect on embryonic development to blastocysts when embryos were cultured at high densities in mSOF supplemented with amino acids.

The ammonium concentration in the present culture medium at the initiation of culture $(0.083 \mathrm{mM})$ was reported to inhibit mouse embryo development [6]. The change of culture medium improved the development of embryos in F1 mice $[6,9,10]$ and sheep [7]. It is likely that bovine embryos are less sensitive to ammonium in the culture medium than the embryos of these other species. However, medium change is recommended for production of calves by in vitro culture and embryo transfer, since ammonium induces fetal retardation and exencephaly in mice [9].

Cultures at higher embryo density improved the developmental rate of embryos to blastocysts regardless of medium change, supporting the previous findings [3, 4, 12]. Embryos produce factor(s) that stimulate their own development. If the embryo density is reduced to some extent, the embryos may not be able to maintain sufficient concentrations of embryotrophic factor(s) to support their development.

The present results of embryo development in the lower density did not agree with the results previously reported by Fukui et al. [5] that medium renewal every $48 \mathrm{hr}$ during culture $(48,96$ and $144 \mathrm{hr}$ ) was detrimental to bovine embryo development to blastocysts. The reason(s) for the discrepancy is unclear. It is, however, likely that medium change at the time of initiating of embryo genome transcription causes a detrimental effect on early bovine

Table 1. Effects of medium change and embryo density on the concentrations of ammonium in the culture medium

\begin{tabular}{|c|c|c|c|}
\hline \multirow{2}{*}{$\begin{array}{l}\text { Medium } \\
\text { Changea) }\end{array}$} & \multirow{2}{*}{$\begin{array}{l}\text { No. of } \\
\text { embryos } \\
\text { per drop } \\
(30 \mu l)\end{array}$} & \multicolumn{2}{|c|}{ Concentration of ammonium (mM) } \\
\hline & & $72 \mathrm{hr}$ & $153 \mathrm{hr}$ \\
\hline \multirow{3}{*}{ No } & 0 & - & $\left.0.586 \pm 0.060^{\mathrm{b}}\right)$ \\
\hline & 3 & - & $0.583 \pm 0.142^{\mathrm{b})}$ \\
\hline & 30 & - & $0.759 \pm 0.063^{\mathrm{c}}$ \\
\hline \multirow{3}{*}{ Yes } & 0 & $\left.0.332 \pm 0.074^{b}\right)$ & $0.392 \pm 0.098^{\mathrm{d})}$ \\
\hline & 3 & $0.382 \pm 0.036^{\mathrm{b})}$ & $0.431 \pm 0.028^{\mathrm{d})}$ \\
\hline & 30 & $\left.0.533 \pm 0.036^{c}\right)$ & $0.481 \pm 0.063^{\mathrm{d})}$ \\
\hline
\end{tabular}

a) Medium change at $72 \mathrm{hr}$ of culture.

bcd) Values (mean \pm SD of 2-6 replicates) with different superscripts differed significantly $(\mathrm{p}<0.05$; ANOVA followed by Fisher's PLSD).

Table 2. Effects of medium change and embryo density on the development of in vitro matured and fertilized bovine oocytes

\begin{tabular}{|c|c|c|c|c|c|}
\hline $\begin{array}{l}\text { Medium } \\
\text { change }\end{array}$ & $\begin{array}{l}\text { No. of } \\
\text { embryos } \\
\text { per drop } \\
(30 \mu l)\end{array}$ & $\begin{array}{l}\text { No. of } \\
\text { replicates } \\
\text { (zygotes) }\end{array}$ & $\%$ of cleaved & $\%$ of blastocysts & $\begin{array}{l}\text { Cell no. in blastocysts } \\
\text { (n) }\end{array}$ \\
\hline \multirow[t]{2}{*}{ No } & 3 & $5(150)$ & $80.0 \pm 5.3$ & $24.7 \pm 3.8$ & $161.8 \pm 8.1$ \\
\hline & 30 & $5(150)$ & $84.0 \pm 8.0$ & $32.0 \pm 3.8$ & $188.6 \pm 10.4$ \\
\hline \multirow[t]{2}{*}{ Yes } & 3 & $5(150)$ & $84.7 \pm 6.9$ & $27.3 \pm 8.6$ & $171.8 \pm 13.2$ \\
\hline & 30 & $5(150)$ & $85.3 \pm 6.9$ & $38.0 \pm 11.9$ & $186.8 \pm 19.4$ \\
\hline \multirow[t]{2}{*}{ Total } & 3 & $10(300)$ & $82.3 \pm 6.3$ & $26.0 \pm 6.4^{\mathrm{b})}$ & $166.8 \pm 11.6^{\mathrm{b})}$ \\
\hline & 30 & $10(300)$ & $84.7 \pm 7.1$ & $35.0 \pm 8.9^{\mathrm{c}}$ & $187.7 \pm 14.7^{\mathrm{c})}$ \\
\hline
\end{tabular}

a) Medium change at $72 \mathrm{hr}$ of culture.

bc) Values (mean $\pm \mathrm{SD}$ ) with different superscripts differed significantly ( $<<0.05$; ANOVA followed by Fisher's PLSD). 
embryonic development due to the loss of embryotrophic factor(s), especially when embryos are being cultured in small numbers. In the previous study [5], embryo-produced embryotrophic factor(s), such as activin [22], might be removed by medium change after $48 \mathrm{hr}$ of culture (8- to 16cell stages), when embryos have high susceptibility to the culture conditions. Further experiments are needed to determine the effect of medium change on the embryo development at various intervals such as 48,72 or $96 \mathrm{hr}$ of culture with different embryo density.

In conclusion, changing the culture medium during culture may not be necessary when in vitro culture technique is used to assess embryo development to blastocysts under the present conditions.

ACKNOWLEDGMENTS. This study was supported by a Grant-in-Aid for Scientific Research (Nos. 09660295 and 10556058) from the Ministry of Education, Science, Sports and Culture, Japan to Y. Takahashi. We thank the Hokkaido Livestock Improvement Association for supplying frozen semen, the Ebetsu Meat Inspection Office for supplying ovaries and Dr. Yamato for guiding the measurement of ammonium concentration.

\section{REFERENCES}

1. Bavister, B. D., Leibfried, M. L. and Lieberman, G. 1983. Biol. Reprod. 28: 235-247.

2. Carolan, C., Lonergan, P., Van Langendonckt, A. and Mermillod, P. 1995. Theriogenology 43: 1115-1128.

3. Donnay, I., Van Langendonckt, A., Auquier, P., Grisart, B., Vansteenbrugge, A., Massip, A. and Dessy, F. 1997. Theriogenology 47: 1549-1561.

4. Ferry, L., Mermillod, P., Massip, A. and Dessy, F. 1994. Theriogenology 42: 445-453.

5. Fukui, Y., Lee, E. S. and Araki, N. 1996. J. Anim. Sci. 74:
2752-2758.

6. Gardner, D. K. and Lane, M. 1993. Biol. Reprod. 48: $377-$ 385 .

7. Gardner, D. K., Lane, M., Spitzer, A. and Batt, P. A. 1994. Biol. Reprod. 50: 390-400.

8. Lane, M. and Gardner, D. K. 1992. Hum. Reprod. 7: 558562.

9. Lane, M. and Gardner, D. K. 1994. J. Reprod. Fertil. 102: 305-312.

10. Lane, M. and Gardner, D. K. 1995. J. Exp. Zool. 271: 356363.

11. Lane, M. and Gardner, D. K. 1997. J. Reprod. Fertil. 109: 153-164

12. O'Doherty, E. M., Wade, M. G., Hill, J. L. and Boland, M. P. 1997. Theriogenology 48: 161-169.

13. Paria, B. C. and Dey, S. K. 1990. Proc. Natl. Acad. Sci. U.S.A. 87: 4756-4760.

14. Partridge, R. J. and Leese, H. J. 1996. Reprod. Fertil. Dev. 8: 945-950.

15. Rieger, D., Loskutoff, N. M. and Betteridge, K. J. 1992. J. Reprod. Fertil. 95: 585-595.

16. Schneider, M., Marison, I. W. and von Stockar, U. 1996. J. Biotech. 46: 161-185.

17. Takahashi, Y. and First, N. L. 1992. Theriogenology 37: $963-$ 978.

18. Takahashi, Y., Hishinuma, M., Matsui, M., Tanaka, H. and Kanagawa, H. 1996. J. Vet. Med. Sci. 58: 897-902.

19. Takahashi, Y. and Kanagawa, H. 1998. J. Vet. Med. Sci. 60: 365-367.

20. Takahashi, Y. and Kanagawa, H. 1998. J. Vet. Med. Sci. 60: 433-437.

21. Wiley, L. M., Yamami, S. and Van Muyden, D. 1986. Fertil. Steril. 45: 111-119.

22. Yoshioka, K., Suzuki, C. and Iwamura, S. 1998. Biol. Reprod. 59: 1017-1022.

23. Zhang, X. and Armstrong, D. T. 1990. Biol. Reprod. 42: 662668. 